\title{
GPR119 agonist enhances gefitinib responsiveness through lactate-mediated inhibition of autophagy
}

\author{
Ji Hye $\mathrm{Im}^{1}$, Keon Wook Kang ${ }^{2}$, Sun Young Kim³, Yoon Gyoon Kim³, Yong Jin An ${ }^{4}$, Sunghyouk Park \\ Byung Hwa Jeong ${ }^{5}$, Song-Yi Choi ${ }^{6}$, Jin-Sun Lee ${ }^{6}$ and Keon Wook Kang ${ }^{*^{*}}$
}

\begin{abstract}
Background: Ligand-dependent activation of the G-protein coupled receptor 119 (GPR119) lowers blood glucose via glucose-dependent insulin secretion and intestinal glucagon-like peptide-1 production. However, the function of GPR119 in cancer cells has not been studied.

Methods: GPR119 expression was assessed by real-time qPCR and immunohistochemistry in human breast cancer cell lines and breast cancer tissues. Cell proliferation and cell cycle analyses were performed by Incucyte ${ }^{\circledast}$ live cell analysis system and flow cutometry, respectively. Autophagy activity was estimeated by western blottings and LC3-GFP transfection.

Results: mRNA or protein expression of GPR119 was detected in 9 cancer cell lines and 19 tissue samples. Cotreatment with GPR119 agonist (MBX-2982 or GSK1292263) significantly potentiated gefitinib-induced cell growth inhibition in gefitinibinsensitive MCF-7 and MDA-MB-231 breast cancer cells. We observed that caspase-3/7 activity was enhanced with the downregulation of BCl-2 in MCF-7 cells exposed to MBX-2982. Gefitinib-induced autophagy is related with cancer cell survival and chemoresistance. GPR119 agonists inhibit gefitinib-induced autophagosome formation in MCF-7 and MDA-MB231 cells. MBX-2982 also caused a metabolic shift to enhanced glycolysis accompanied by reduced mitochondrial oxidative phosphorylation. MBX-2982 increased intracellular $(\sim 2.5 \mathrm{mM})$ and extracellular lactate $(\sim 20 \mathrm{mM})$ content. Gefitinib-mediated autophagy was suppressed by $20 \mathrm{mM}$ lactate in MCF-7 cells.

Conclusions: GPR119 agonists reduced mitochondrial OXPHOS and stimulated glycolysis in breast cancer cells, with consequent overproduction of lactate that inhibited autophagosome formation. Because autophagy is crucial for the survival of cancer cells exposed to TKIs, GPR119 agonists potentiated the anticancer effects of TKIs.
\end{abstract}

Keywords: Autophagy, Breast cancer, Gefitinib, GPR119 agonist, Lactate

\section{Background}

Anti-epidermal growth factor receptor (EGFR) therapy is an effective way to inhibit proliferation of many cancer types such as non-small cell lung cancer (NSCLC) and colorectal cancer [1]. However, EGFR-tyrosine kinase inhibitor (TKI) alone or in combination therapy with paclitaxel or docetaxel had been used for breast cancer patients in clinical trials, but both therapies failed [2]. Thus, it may be necessary to investigate the chemoresistance mechanism(s) to EGFR TKI for breast cancer patients.

\footnotetext{
* Correspondence: kwkang@snu.ac.kr

${ }^{1}$ College of Pharmacy and Research Institute of Pharmaceutical Sciences,

Seoul National University, Seoul, Republic of Korea

Full list of author information is available at the end of the article
}

Macroautophagy or autophagy is a lysosomal degradative process that recycles cellular components and maintains cell homeostasis [3]. In autophagy, double-membrane vesicles (autophagosomes) sequestrate selected substrates and fuse with lysosomes (autolysosomes). Autophagy dysfunction results in the accumulation of intracellular damaged proteins, causing neurodegeneration or cardiac hypertrophy [4]. The effect of autophagy activation on a cancer cell survival is controversial. Accelerated autophagy is believed to be an anticancer mechanism for a variety of agents. Nur77 agonists induce autophagic cell death in melanoma cells [5]. Rapamycin, an mTOR inhibitor, induces autophagic cell death in MG63 osteosarcoma cells [6]. In contrast, autophagy is actively involved in cancer cell resistance to

(c) The Author(s). 2018 Open Access This article is distributed under the terms of the Creative Commons Attribution 4.0 International License (http://creativecommons.org/licenses/by/4.0/), which permits unrestricted use, distribution, and 
anticancer agents through recycling of cellular energy sources and components. For instance, treatment with chloroquine, an autophagy flux inhibitor, overcomes anti-estrogen resistance of MCF-7 cells [7]. Chloroquine also enhanced a cytotoxicity of temozolomide in glioma cells [8]. Thus, potential role of autophagy in cancer chemotherapy remains elusive.

Lipid-sensing G-protein-coupled receptors (GPCRs) are highly expressed in pancreatic $\beta$-cells and implicated with metabolic symdroms [9]. Previous studies examined the diverse functions of lipid-sensing receptors in the development and progression of cancer. GPR120 is activated by $\omega-3$ fatty acids and promotes tumor progression and angiogenesis in prostate cancer $[10,11]$. Activations of GPR43 and GPR109A which sense short-chain fatty acids suppress cell proliferation of colon cancer cells and tumorigenesis of breast cancer cells [12, 13]. Oleic acid, an endogenous ligand of GPR40, promotes the proliferation of breast cancer cells, but TAK-875, a synthetic ligand of GPR40, inhibits the tumor growth of melanoma $[14,15]$. GPR119 is activated by endogeneous oleoylethanolamine(OEA) and mainly coupled to Gos signaling [9]. Although GPR119 is a promising target for type II diabetes and fatty liver diseases [16], a role of GPR119 in cancer has not been studied. Here, we found that GPR119 was ubiquitously expressed in human breast cancer cell lines and tumor tissues. We investigated in vitro and in vivo combination effects of GPR119 agonists with TKIs in breast cancer and hepatoma cells, and clarified the mechanistic basis for the anticancer effects of GPR119 agonists, focusing on autophagy inhibition.

\section{Methods}

\section{Cell culture}

Breast cancer cell lines (MCF-7, MDA-MB-231 and TamR-MCF-7) were cultured in Dulbecco's modified Eagle's medium (DMEM) containing 10\% fetal bovine serum and $1 \%$ penicillin-streptomycin. MCF-10A was cultured in media as described previously [17]. Other breast cancer cell lines were cultured in RPMI1640 media. Hepatocellular carcinoma cell lines (HepG2 and HepG2-X cells) were cultured in DMEM containing 10\% fetal bovine serum and $1 \%$ penicillin-streptomycin.

\section{Antibodies and reagents}

MBX-2982, GSK1292263, gefitinib and sorafenib were obtained from Medchemexpress (Monmouth Junction, NJ, USA). Chloroquine, 3-methyladenine (3-MA) and other reagents were purchased from Sigma-Aldrich (St. Louis, MI). Anti-GPR119 antibody was supplied from Abcam (Cambridge, UK). Anti-monocarboxlyate transporter (MCT) 1, anti-MCT2, anti-MCT4, anti-lactate dehydrogenase (LDH) A, anti-LDHB antibodies were purchased from Santa Cruz Biotechnology (Dallas, TX,
USA). Other antibodies including LC3B were supplied from Cell Signaling Technology (Danvers, MA, USA). GFP-LC3B plasmid were kindly donated from Dr. Kim J (University of Florida, Gainesville, FL, USA).

\section{Incucyte ${ }^{\circledast}$ live cell analysis system for the determination of cell proliferation and caspase-3/7 activity}

Cells were seeded in 96 well plate and real-time monitored by Incucyte ${ }^{\circ}$ system (Essenbio science, Ann Arbor, MI, USA). Sets of images were acquired and analyzed by Incucyte ${ }^{\circ}$ basic software. Caspase3/7 activity in apoptotic cells was visualized with Kinetic caspase 3/7 reagent (cat.4440, Essenbio science). The half maximal inhibitory concentration $\left(\mathrm{IC}_{50}\right)$ values were calculated through non-linear regression analysis using SigmaPlot ver. 12 (Systat Software Inc., San Jose, California, USA).

\section{Western blot analysis}

Cells were washed with cold phosphate-buffered saline (PBS) and lysed in lysis buffer (150 mM Tris-Cl (pH.7.6), $10 \%$ NP-40, protease inhibitors and phosphatase inhibitors) and centrifuged at $16000 \mathrm{~g}, 4{ }^{\circ} \mathrm{C}$. The proteins were separated in sodium dodecyl sulfate (SDS)-polyacrylamide gel electrophoresis (PAGE) and transferred to nitrocellulose membrane. The membranes were incubated with specific primary antibodies diluted in 5\% skim milk in Tween 20-containing PBS and corresponding secondary antibodies.

Reverse transcriptase-polymerase chain reaction (RT-PCR) and quantitative real-time PCR (qPCR)

Total RNA was extracted using Trizol reagent (Invitrogen, Carlsbad, CA, USA). cDNA was synthesized by reverse transcriptase kit (iNtRON, Seoul, South Korea) and PCR was performed using specific primers: human GPR119 F: 5'-CTCCCTCATCATTGCTACTAA-3', R: 5'-ACAGCCA GATTCAAGGTG-3'. GAPDH F: 5'-AGCCACATC GCTCAGA CAC-3', R: 5'-GCCCAATACGACCAAATC C-3'. The SYBR Green qPCR amplification was conducted with MiniOpticon real time PCR detection system (Bio-Rad laboratories Inc., Hercules, CA, USA).

\section{Immunohistochemistry}

Forty-nine human breast cancer tissues were obtained from Chungnam National University hospital (IRB approval \#: CNUH 2015-03-001). Tissue sections were processed from formalin-fixed paraffin-embedded tissue samples according to previously described method [18]. Tissue sections were stained with anti-GPR119 or anti-estrogen receptor $\alpha$ antibody as primary antibody and images of tissue sections were taken by a bright-field microscopy. In statistics, the pearson's correlation coefficient between GPR119 and clinical pathology was calculated from sigma plot. 
1H-NMR analysis for lactate and glucose determination Cell lysates and media were dried using speed vacuum concentrator and reconstructed in appropriate buffer (2 $\mathrm{mM} \mathrm{Na}_{2} \mathrm{HPO}_{4}, 5 \mathrm{mM} \mathrm{NaH} \mathrm{PO}_{4}, 0.025 \%$ trimethylsilyl propionate in $99.9 \%$ D2O). Proton-NMR (1H-NMR) spectroscopy was performed by Bruker $500 \mathrm{MHz}$ spectrometer (Bruker Coperation, Billerica, MA, USA). Lactate was also determined by lactate assay kit (Abcam, Cambridge, UK). Sample preparation and protocols were performed according to the manufacture's instruction.

\section{Xenograft analysis}

Female Balb/c-nu mice were purchased from Raonbio (Seoul, South Korea). Animal studies were performed according to the regulation and an approval of Seoul National University Institutional Animal Care and Use Committee (Approval \#: SNU-140106-1). Briefly, five-week-old female BALB/c-nude mice were inoculated with cancer cells in flank side. The mice were intraperitonially injected with $17-\beta$-estradiol $(2 \mathrm{mg} / \mathrm{kg} /$ day $)$. Gefitinib ( $1 \mathrm{mg} / \mathrm{kg} /$ day, 5 times a week) and MBX-2982 (10 mg/kg/day, 5 times a week) were orally administered to the mice for 40 days.

\section{Transmission Electron microscopy (TEM)}

Cells were fixed with karnovskys fixative and washed 3 times with $2 \mathrm{ml} 0.05 \mathrm{M}$ cacodylate buffer and post-fixed with $2 \%$ osmium tetroxide for $2 \mathrm{~h}$. After washing with distilled water, cells were stained with $0.5 \%$ uranyl acetate and dehydrated with a series of ethanol and propylene oxide. Cells were embeded in spurr's resin and polymerized at $70{ }^{\circ} \mathrm{C}$. The blocks were trimmed to ultrathin section using an ultramicrotome (EM UC7, Leica, Wetzlar, Germany) and observed with Transmission Electron Microscope (JEM1010, JEOL, Tokyo, Japan).

\section{siRNA transfection and shRNA infection} siGENOME SMARTpools systems for ATG7 (cat \# MQ-020112-01-0002) knockdown and scramble (cat \# D-001206-13-05) were purchased from Dharmacon (Lafayette, CO). MCF-7 cells and HepG2 cells were transfected with siRNA using FuGENE ${ }^{\oplus}$ HD Transfection Reagent (Promega, Madison, WI, USA). shRNA lentivirus particles for GPR119 (cat \# SHCLNV-NM_178471) and Nontarget control (cat \# SHV0002) were purchased from Sigma-Aldrich. MCF-7 cell was incubated with lentivirus particles and hexamidine bromide. Stable cell lines were generated by puromycin treatment for more than 2 weeks.

\section{Mitochondria enrichment fraction isolation}

Crude mitochondria were isolated by sucrose gradient purification. Cells were seeded in $150 \mathrm{~mm}^{2}$ culture plate and treated with MBX-2982 for $6 \mathrm{~h}$. The cells were washed 3 times with PBS, harvested with trypsin and suspended in $1 \mathrm{ml}$ NKM buffer (1 mM Tris-Cl, $\mathrm{pH} 7.4$, $0.13 \mathrm{M} \mathrm{NaCl}, 5 \mathrm{mM} \mathrm{KCl}, 7.5 \mathrm{mM} \mathrm{MgCl} 2$ ). The cell mixture was centrifuged and suspended in $0.6 \mathrm{ml}$ homogenization buffer (10 mM Tris- $\mathrm{Cl}, \mathrm{pH}$ 6.7, $10 \mathrm{mM}$ $\mathrm{KCl}, 0.15 \mathrm{mM} \mathrm{MgCl}_{2}$ ) and homogenized using a pestle and glass potter. The homogenate was mixed with $0.1 \mathrm{ml}$ $2 \mathrm{M}$ sucrose and centrifuged at $1200 \mathrm{~g}$ for $5 \mathrm{~min}$ and repeated twice. The supernatant was transferred and centrifuged at $7000 \mathrm{~g}$ for $10 \mathrm{~min}$.

\section{Mitochondrial function assay}

OCR and ECAR were monitored using an XFp analyzer (Seahorse Bioscience, North Billerica, MA, USA) and XFp cell mito-stress test kit (Seahorse Bioscience). $3 \times$ $10^{3}$ cells were seeded in XFp cell culture miniplate and growth media were replaced with XFp assay media $1 \mathrm{~h}$ before the test. All the reagents and assay conditions were followed by manufacturer's instructions.

\section{Flow cytometry analysis}

For cell cycle analysis, cells were fixed in 70\% ethanol overnight, washed twice with PBS and suspended in staining buffer (0.1\% Triton X-100, $0.2 \mathrm{mg} / \mathrm{ml}$ RNase A, $1 \mu \mathrm{g} / \mathrm{ml}$ Propidium iodide(PI) in PBS) for $10 \mathrm{~min}$. For apoptosis detection, cells were trypsinized, washed with PBS and stained with PI and annexin $\mathrm{V}$ in binding buffer (10 mM HEPES, $\mathrm{pH} 7.4,140 \mathrm{mM} \mathrm{NaCl}, 2.5 \mathrm{mM} \mathrm{CaCl}_{2}$ ) for $15 \mathrm{~min}$. The stained cells were washed twice with PBS and analyzed by FACS caliber (BD science, Franklin Lakes, NJ, USA).

\section{Statistical analyses}

Data are presented as mean \pm S.D. or S.E. Student's t-test was used to analyze differences between experimental groups. Values of $* p<0.05$ or $* * p<0.01$ or $* * * p<0.005$ were considered significant.

\section{Results \\ GPR119 expression in human breast cancer cells and tumor tissues}

We found GEO datasets containing GPR119 transcript levels in various cancer cell types (Fig. 1a, upper panel). Although significant differences were not seen between benign and malignant cancer tissues, GPR119 mRNA was identified from human breast cancer tissue datasets (Fig. 1a). By public dataset analysis, GPR119 mRNA was not associated with cancer metastasis or pathology classification of breast cancer (Fig. 1a, lower panels). We further quantified GPR119 mRNA expression in 11 breast cancer cell lines and MCF10A mammary epithelial cell line by real-time qPCR analyses. Compared to MCF-10A, GPR119 mRNA was amplified in seven breast cancer cell lines, and there were no correlation between existence of hormone receptors or Her2 and GPR119 exprtession (Fig. 1b). 
A
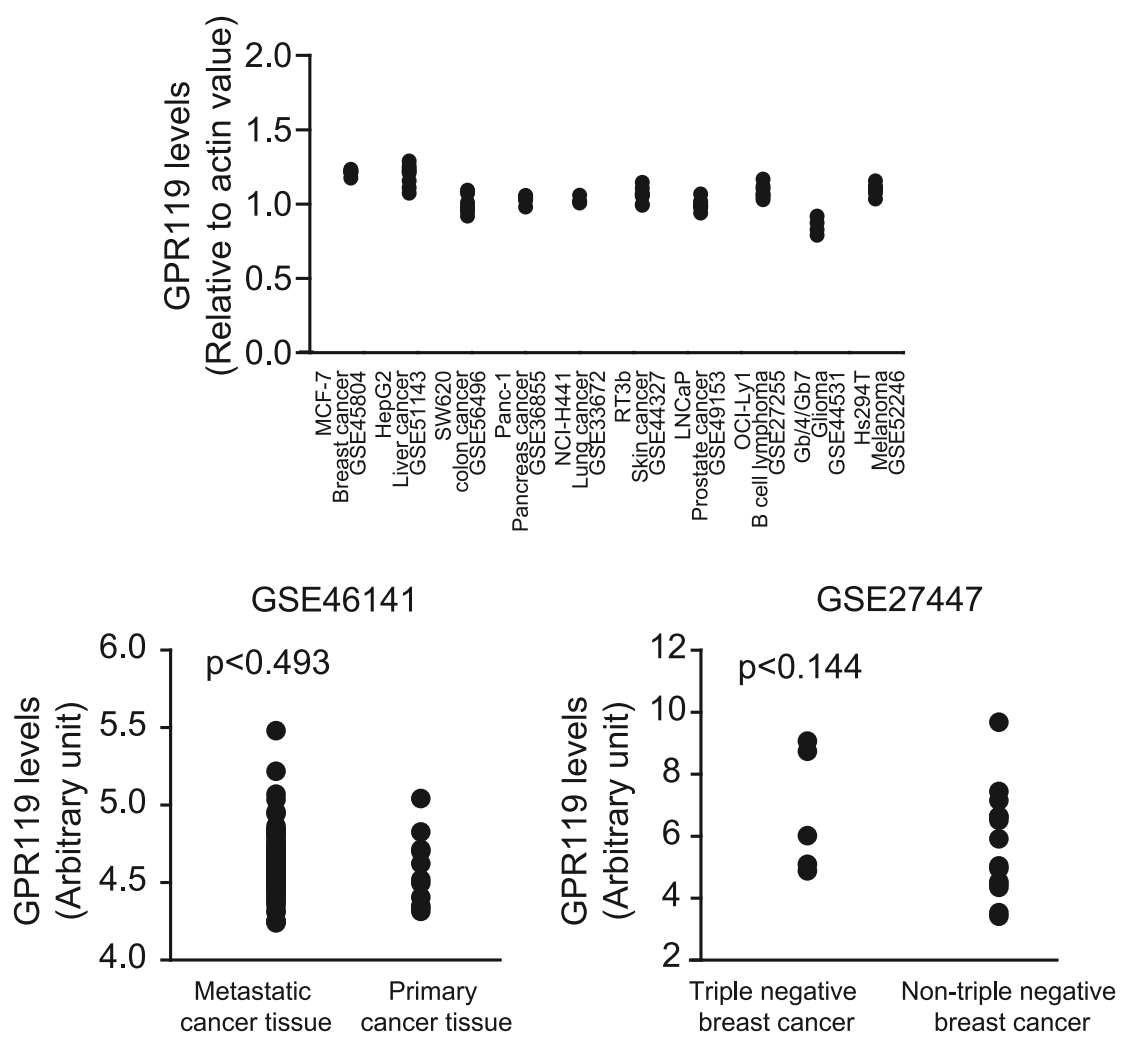

B

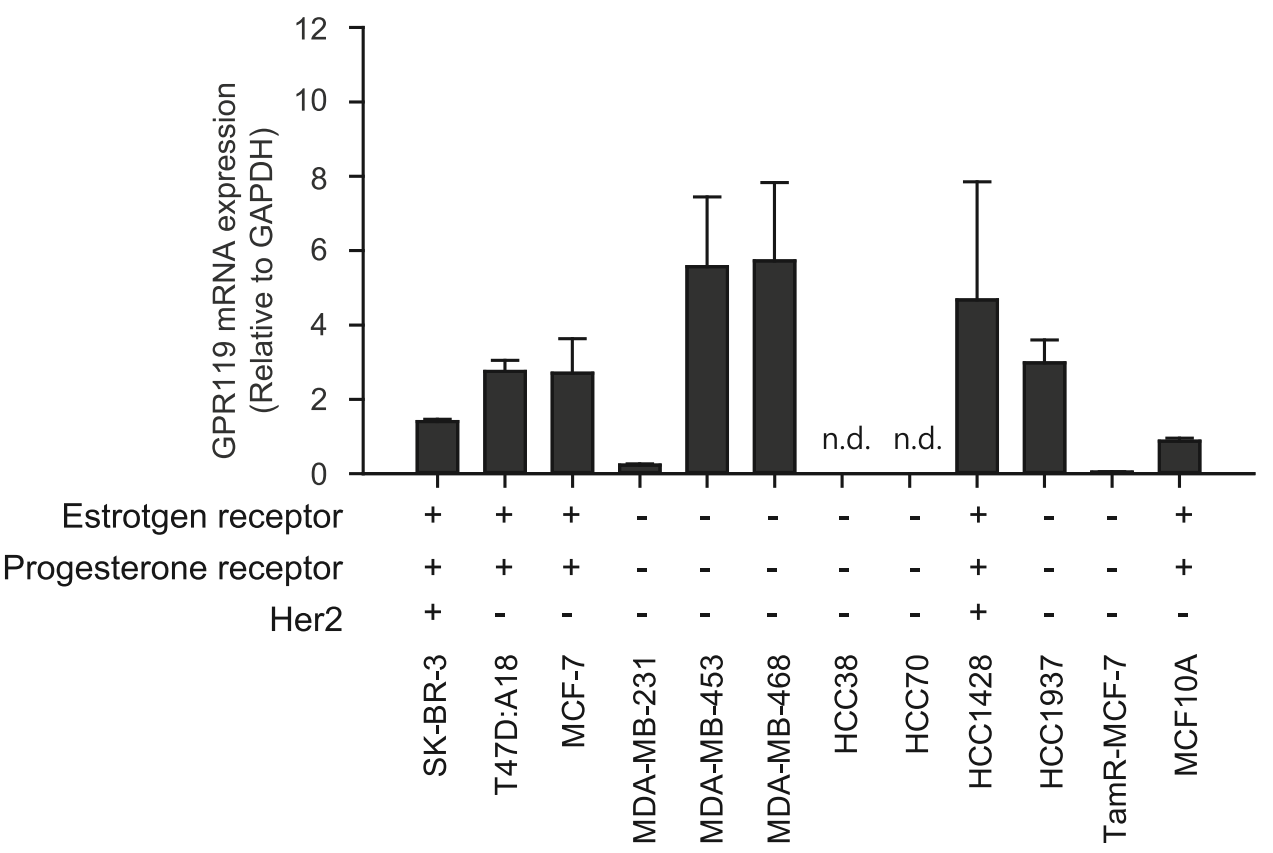

Fig. 1 (See legend on next page.) 
(See figure on previous page.)

Fig. 1 GPR119 expression in human breast cancer cells and tumor tissues. a Gene Expression Omnibus profiles of GPR119 in human breast cancer. Upper, relative mRNA levels of GPR119 in human cancer cell lines; lower, GPR119 mRNA expression in metastatic and primary breast cancer tissues; GPR119 mRNA expression in triple negative breast cancer (TNBC) and Non-TNBC tissues. b Expression levels of GPR119 mRNA in various human breast cancer cell lines were verified by real-time qPCR. MCF10A cells were used as normal mammary epithelial cells

Immunohistochemistry showed that 19 samples from 49 human breast cancer tissues were GPR119 positive, but there were no remarkable changes in GPR119 expression depending on TMN stages and tumor stages of patients or estrogen receptor (ER)- $\alpha$ (Table 1). Thus, GPR119 was constitutively expressed in human breast cancer.

\section{Proliferation inhibition and intrinsic apoptosis by GPR119 agonist in breast cancer cells}

Aberrant EGFR signaling is involved in poor prognosis of many types of cancer. One of the current treatment options for breast cancer is EGFR-TKI as well as anti-hormone agents [19]. However, clinical outcomes of EGFR-TKI are less successful than expected [20]. Hence, we assessed whether GPR119 agonist provides synergistic benefit with EGFR-TKI in human breast cancer. To assess the potential synergism of two drugs, 'isobole model' has been frequently used [21]. In the isobole model, the position of coordinates of drug doses displayed the effect of combination (additive, synergistic, antagonistic effect). The $\mathrm{IC}_{50}$ values of gefitinib and MBX-22982 in cell proliferation of MCF-7 cells (a

Table 1 Correlation between GPR119 expression and pathological parameters of breast cancer patients

\begin{tabular}{|c|c|c|c|}
\hline \multirow[t]{2}{*}{ Parameter } & \multicolumn{2}{|c|}{ GPR119 (IHC) } & \multirow{2}{*}{$\begin{array}{l}\text { Pearson } \\
\text { correlation } \\
\text { ( } p \text {-value) }\end{array}$} \\
\hline & Negative & Positive & \\
\hline T stage & & & 0.535 \\
\hline $\mathrm{T} 1$ & 13 & 8 & \\
\hline $\mathrm{T} 2$ & 17 & 11 & \\
\hline T3 & 0 & 0 & \\
\hline N stage & & & 0.892 \\
\hline NO & 18 & 10 & \\
\hline N1 & 9 & 8 & \\
\hline $\mathrm{N} 2$ & 3 & 1 & \\
\hline M stage & & & No value \\
\hline Mo & 30 & 19 & \\
\hline M1 & 0 & 0 & \\
\hline Tumor stage & & & 0.896 \\
\hline 1 & 9 & 5 & \\
\hline 2 & 18 & 13 & \\
\hline 3 & 3 & 1 & \\
\hline ER alpha (IHC) & & & 0.0898 \\
\hline Negative & 9 & 4 & \\
\hline Positive & 21 & 15 & \\
\hline
\end{tabular}

representative ER+ breast cancer cell line) were $21.2 \mu \mathrm{M}$ and $18.8 \mu \mathrm{M}$, respectively. The dose pairs of the combination of gefitinib and MBX-2982 were below the isobole indicating the synergistic effect of the drug combination (Fig. 2a). We also calculated the isobologram of the drug combination on MDA-MB-231 cells [a triple negative breast cancer (TNBC) cell line] and observed the same results (Fig. 2b). Another GPR119 agonist used in clinical trials, GSK1292263, also potentiated the anti-proliferative effect of gefitinib on MCF-7 and MDA-MB-231 cells (Additional file 1: Figure S1A and B). We further tested the combined effects of GPR119 agonist with gefitinib on cell proliferation of MDA-MB-468 (a TNBC cell line) and SK-BR-3 cells (a Her2+ and ER+ breast cancer cell line). Cotreatment with $3 \mu \mathrm{M} \mathrm{MBX}-2982$ and $100 \mathrm{nM}$ gefitinib additively suppressed cell proliferation of MDA-MB-468 or SK-BR-3 cells (Additional file 1: Figure S1C). The data suggest that GPR119 aognist with gefitinib synergistically inhibits proliferation of breast cancer cells.

We then assessed the effect of OEA (endogenous GPR119 ligand) on proliferation of MCF-7 cells. Because $\mathrm{EC}_{50}$ values of MBX-2982 and OEA for GPR119 are $3.9 \mathrm{nM}$ and $0.2-5 \mu \mathrm{M}$, respectively [22], pharmacological potency of MBX-2982 is 51.3-1282.1 fold higher than OEA. When we assessed cell proliferation inhibitory effect of OEA $(10 \mathrm{mM})$ in MCF-7 cells, the compound did not change the basal cell growth (Additional file 1: Figure S1D). However, co-treatment with OEA and gefitinib significantly reduced cell proliferation of MCF-7 cells compared to gefitinib alone group (Additional file 1: Figure S1D).

To examine a possible mechanism for the anti-cancer effects of GPR119 agonists, flow cytometry analyses were performed after exposure of MCF-7 cells to MBX-2982 for $48 \mathrm{~h}$. Annexin V and propidium iodide (PI) staining revealed that a late-apoptotic population was 6.9-fold enhanced in a MBX-2982-gefitinib cotreated group compared to the gefitinib-alone group (Fig. 2c). Representative apoptosis indices, caspase $3 / 7$ activity and poly (ADP-ribose) polymerase (PARP) cleavage also increased with cotreatment for $36 \mathrm{~h}$ (Fig. $2 \mathrm{~d}$ and e). The relative ratio of $\mathrm{Bcl}-2 /$ Bax expresion represents intrinsic apoptosis marker, and caspase- 8 activation is related with extrinsic apoptosis pathway [23]. Although Bax expression was not altered, Bcl-2 expression was decreased by cotreatment with MBX-2982/gefitinib (Fig. 2f). Changes in cleaved caspase-8 (active form) were not observed in all treatment groups (Fig. 2g). We further analyzed cell cycle progression and the expression of cell cycle marker proteins. Cell population percentage of $\mathrm{S}$ phase was 


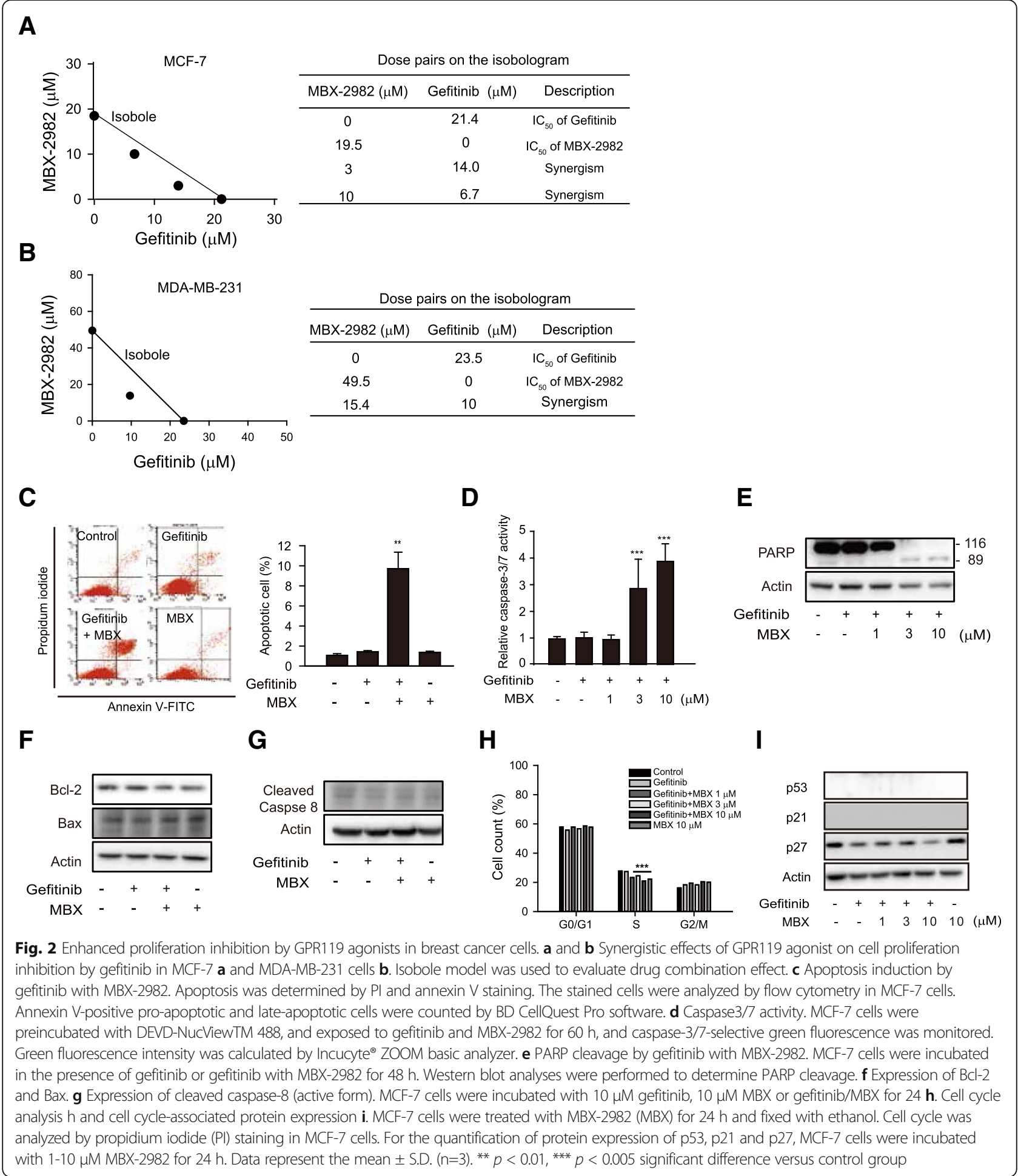

significantly reduced by co-treatment with gefitinib and MBX-2982, and p27 expression was also remarkably suppressed (Fig. $2 \mathrm{~h}$ and $\mathrm{i}$ ). These results indicate that the anti-proliferative effect of GPR119 agonist seemed to be related with impairment of cell cycle progression as well as stimulation of late apoptosis.

\section{Inhibition of EGFR-TKI-induced autophagy by MBX-2982} in breast cancer cells

Autophagy process triggered by autophagosome formation shows dual functions; cell survival and cell death. Chemotherapies including EGFR-TKI induce functional autophagy in diverse cancer cells types [24]. To confirm if gefitinib 
induces autophagy in breast cancer cells, we determined LC3B II expression as a marker of autophagosome formation [25]. LC3B II protein increased with gefitinib treatment in MCF-7 and MDA-MB-231 cells (Fig. 3a). Transmission electron microscopy (TEM) showed that a lipid bilayer structure in the cytoplasm (autophagosomes) formed in MCF-7 cells with gefitinib treatment (Fig. 3b). When ATG7 was silenced by siRNA transfection to block autophagy, gefitinib-induced inhibition of cell proliferation was potentiated (Fig. 3c), suggesting that gefitinib-induced autophagy is a survival mechanism of cancer cells.

Gefitinib-induced LC3B II expression was suppressed in MCF-7 and MDA-MB-231 cells by MBX-2982 (Fig. 3d). GSK1292263 also inhibited conversion to LC3B II in response to gefitinib (Fig. 3e). Chloroquine, a blocker of autophagolysosome formation, accumulates autophagosomes in cells [25]. We confirmed these results using MCF-7 cells transfected with a green fluorescence protein (GFP)-tagged LC3B overexpression plasmid. GFP fluorescence was ubiquitous in whole cells after vehicle treatment, while green punctuate structures were observed in gefitinib-treated MCF-7 cells, and the number of GFP puncta was diminished by MBX-2982 treatment (Fig. 3f, left). In LC3B puncta formation assays with red fluorescence protein (mCherry) tagging, the number of puncta significantly decreased with MBX-2982 treatment (Fig. 3f, right). We then tested the effects of MBX-2982 on tumor growth of xenograft implants of MCF-7 cells. Because MCF-7 cells show hormone-dependent growth, 17- $\beta$-estrogen $(2 \mathrm{mg} / \mathrm{kg} /$ day) was subcutaneously injected into tumor-bearing mice. Tumor growth was moderately reduced by oral administration of gefitinib, whereas tumor growth was completely suppressed by co-administration of gefitinib with MBX-2982 (Fig. 3g). The data demonstrate that GPR119 agonist inhibits autophagosome formation in cancer cells treated with EGFR-TKI and possess anticancer effects against breast cancer.

\section{Cell proliferation inhibition by GPR119 agonist and target chemotherapies}

We further tested synergistic effects of GPR119 agonist with other target therapeuctic agents, tamoxifen and sorafenib. Tamoxifen is a selective estrogen receptor modulator and is widely used to treat or prevent estrogen receptor-positive breast cancer [26]. Cell proliferation of MCF-7 cells was partially inhibited by $0.3-10 \mu \mathrm{M}$ 4-hydroxytamoxifen (4-OHT), an active metabolite of tamoxifen, but concentration-dependency was not observed (Fig. 4a). Whereas, combination of $0.3 \mu \mathrm{M}$ 4-OHT with MBX-2982 or GSK1292263 additively inhibited cell proliferation of MCF-7 cells (Fig. 4b and c). Moreover, 4-OHT-induced LC3B II expression was reversed by MBX-2982 co-treatment (Fig. 4d).
Sorafenib as a multi-kinase inhibitor is now used for the treatment of hepatocellular carcinoma [27]. When we determined GPR119 mRNA expression in HepG2, SNU-449 and SK-Hep1 hepatocellular carcinoma cell lines, GPR119 mRNA was similarly detected in HepG2 and SNU-449 cells, but its expression level was relatively low in SK-Hep1 cells (Fig. 4e). We also found that cell proliferation of HepG2 cells, a human hepatoma cell line was additively inhibited by the combination of sorafenib with MBX-2982 (Fig. 4f). In a similar pattern to MCF-7 cells treated with gefitinib, LC3B II expression was increased in HepG2 cells exposed to sorafenib (Fig. 4g), and inhibitory effect of sorafenib on cell proliferation was potentiated by ATG7 siRNA transfection (Fig. 4h). Moreover, sorafenib-induced LC3B II expression was inhibited by MBX-2982 in HepG2 cells (Fig. 4i), and apoptotic markers such as cleaved forms of caspase- 3 and PARP were enhanced by cotreatment with sorafenib and MBX-2982 in HepG2 cells (Fig. 4j). We also tested the in vivo effects of MBX-2982 on xenograft implants of HepG2-X cells, a HepG2 subclone for xenograft. Co-administration of MBX-2982 with sorafenib synergistically inhibited tumor growth of HepG2-X cells (Fig. 4k). These results indicate that cancer cells induce autophagy in response to target therapies as a survival mechanism and GPR119 agonist possesses anticancer effects via autophagy inhibition.

\section{GPR119 signaling in autophagy inhibition by MBX-2982}

We established GPR119 knockdown cells by shRNA infection to assess whether autophagy inhibition by MBX-2982 was due to target receptor-mediated response. MCF-7 cells were infected with shGPR119 lentivirus and puromycin-resistant GPR119 knockout clones of MCF-7 cells were selected. GPR119 mRNA was determined by quantitative RT-PCR (Fig. 5a). MBX-2982 inhibited gefitinib-induced LC3B II protein expression in nontargeted shRNA-infected MCF-7 cells. GPR119 knockdown reversed the inhibition of LC3B II expression by MBX-2982 (Fig. 5b), implying that GPR119 signaling was required for the inhibitory effect of MBX-2982. Moreover, the coadministration of gefitinib with MBX-2982 did not reduce the tumor volume in xenografts implanted with shGPR119-MCF-7 cells (Fig 5c), which imply that GPR119 signaling is required for anti-cancer effect of MBX-2982.

Stimulation of GPR119 coupled to Gos results in cAMP increase and protein kinase A (PKA) activation [28]. When we determined reporter activity using a cAMP response element (CRE) to represent intracellular cAMP production, $10 \mu \mathrm{M}$ MBX-2982 increased the luciferase reporter activity (Fig. 5d). However, cAMP pathway inhibition with TK5720, a specific PKA inhibitor, did not restore the diminished LC3B II expression by MBX-2982 in MCF-7 cells (Fig. 5e). Because the 
A

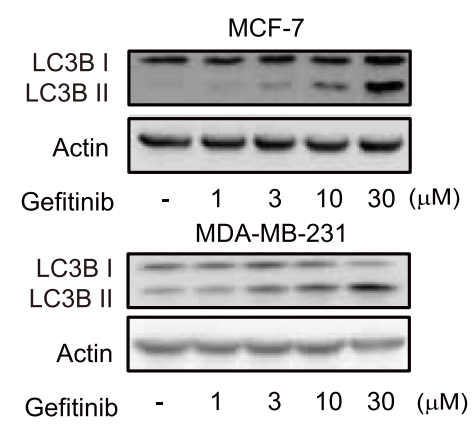

D

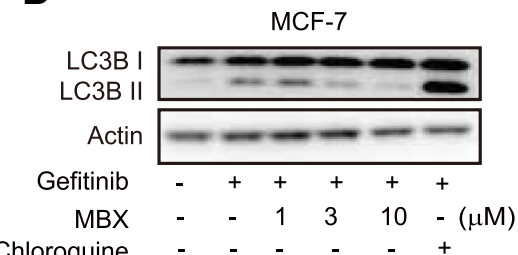

B

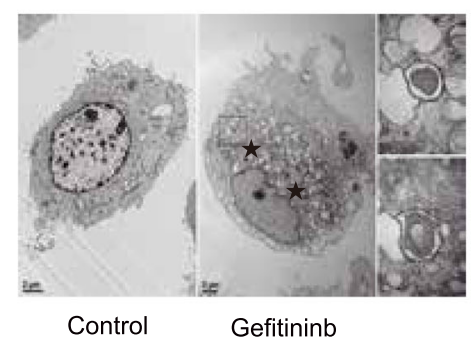

C

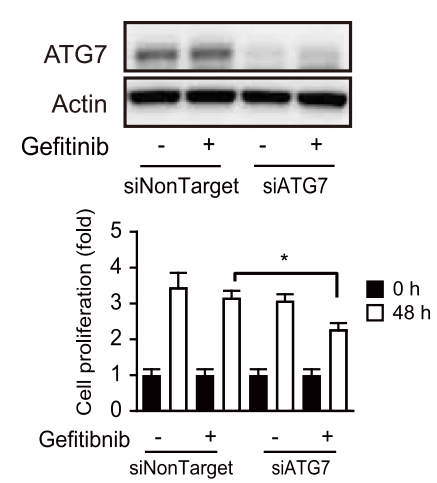

E

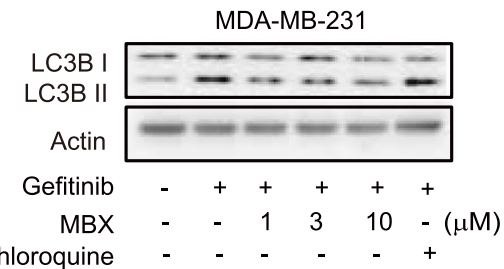

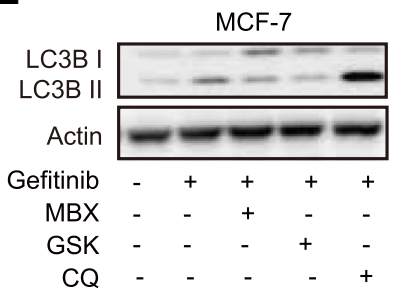

F

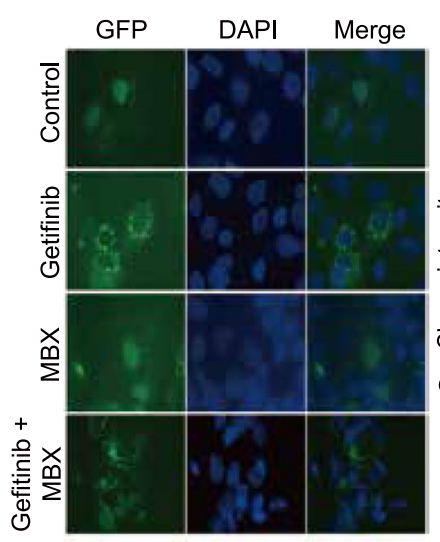

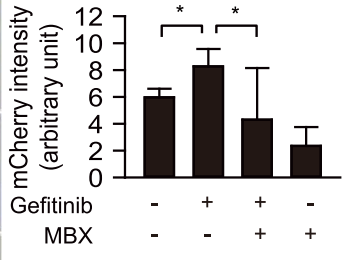

\section{G}
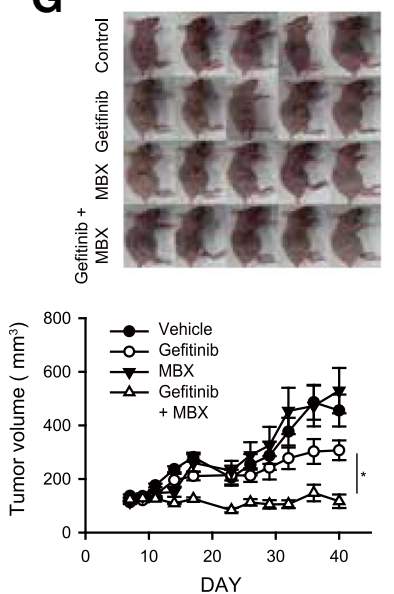
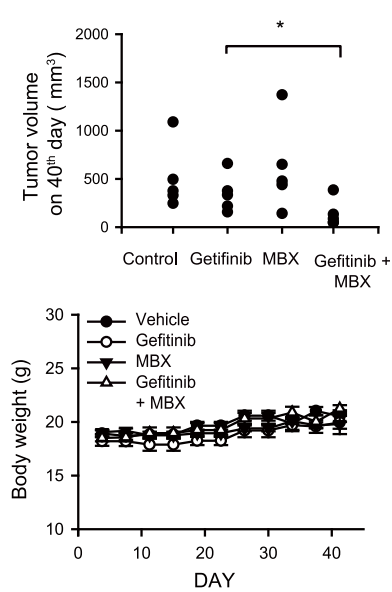

Fig. 3 Inhibition of gefitinib-induced autophagy by GPR1 19 ligands in breast cancer cells. a Autophagy induction by gefitinib in human breast cancer cells. LC3B I/II were measured by immunoblottings in breast cancer cells (MCF-7 and MDA-MB-231 cells). Cells were incubated with 1-30 $\mu$ M gefitinib for 24 h. b Autophagosome formations in gefitinib-treated MCF-7. Autophagosome formation was visualized by TEM in MCF-7 cells. Cells were incubated with $10 \mu \mathrm{M}$ gefitinib for $24 \mathrm{~h}$. Star marks indicate double lipid layer vesicle structures. c Effect of ATG7 siRNA on anti-proliferative effect of gefitinib. ATG7 expression was detected by western blotting after siATG7 transfection (upper) and cell proliferation was monitored by Incucyte ${ }^{\circledR}$ ZOOM basic analyzer in MCF-7 cells (lower). Data represent the mean \pm S.D. $(n=6)$. $\mathbf{d}$ Inhibition of gefitinib-induced autophagy formation by MBX-2982 (MBX). LC3B I/II were measured by western blottings in breast cancer cells incubated with $10 \mu \mathrm{M}$ gefitinib in the presence or absence of 1-10 $\mu \mathrm{M}$ MBX or 3 HM chloroquine. e Inhibition of gefitinib-induced autophagy formation by GSK1292263 (GSK). LC3B I/II were measured by western blottings in MCF-7 cells incubated with $10 \mu \mathrm{M}$ gefitinib, $10 \mu \mathrm{M}$ MBX, $10 \mu \mathrm{M}$ GSK or $3 \mu \mathrm{M}$ chloroquine for $24 \mathrm{~h}$. f Inhibition of autophagosome puncture formation by MBX. Green fluorescence puncta were detected by fluorescence microscopy after LC3-GFP transfection in MCF-7 cells (left). Red fluorescence was calculated in MCF-7 cells after mCherry-GFP-LC3 plasmid transfection by Incucyte ${ }^{\circledast}$ ZOOM basic analyzer (right). MCF-7 cells were incubated with 10 $\mu \mathrm{M}$ gefitinib in the presence or absence of $10 \mu \mathrm{M}$ MBX. Data represent the mean \pm S.D. $(n=3)$. $\mathbf{g}$ Tumor growth of MCF-7 xenograft was monitored for 40 days. Data represent the mean \pm S.E. $(n=5) .{ }^{*} p<0.05$, significant difference between the indicated two groups 


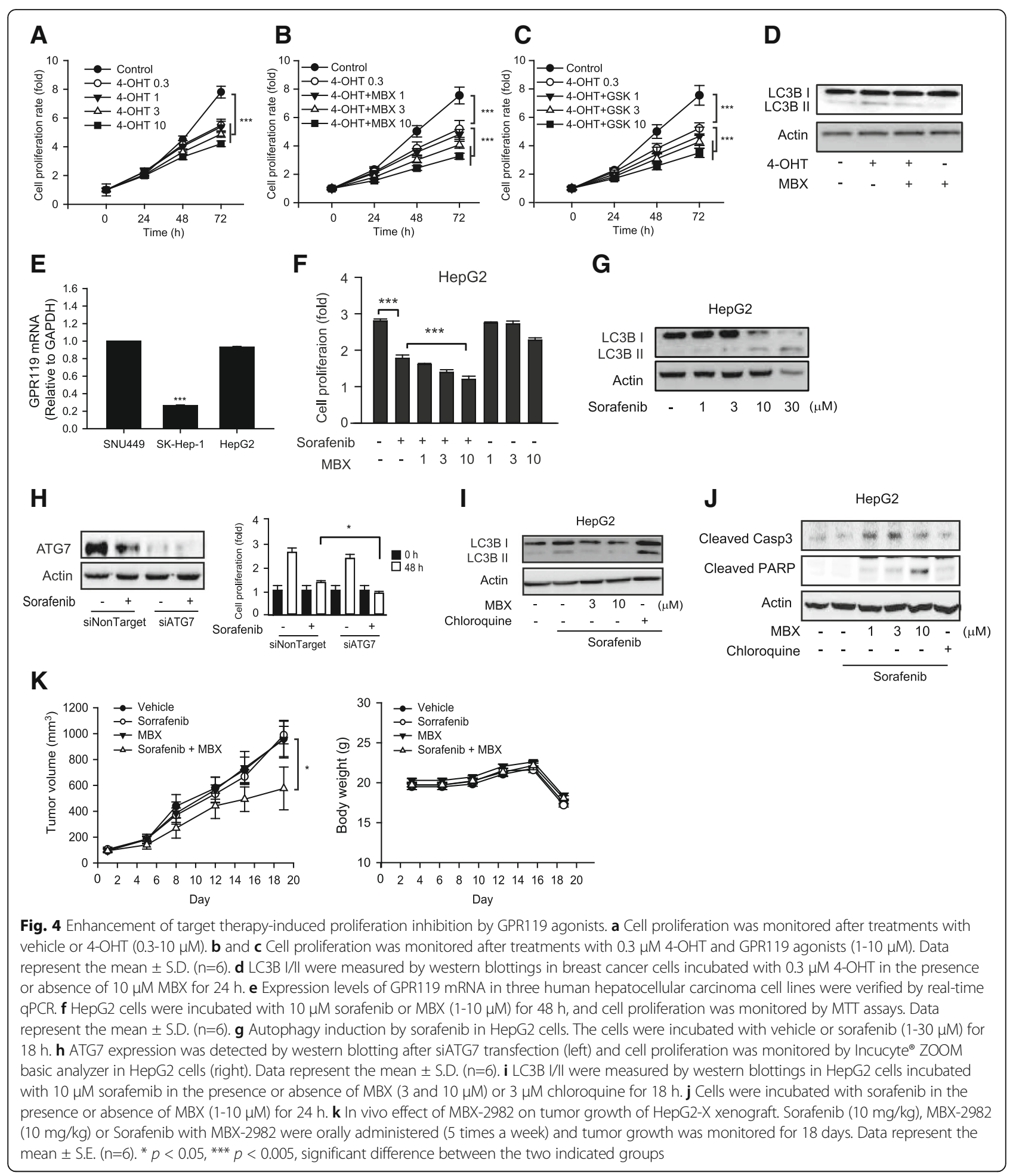

mTORC1 pathway suppresses ULK1 which initiates autophagosome formation, we hypothesized that mTORC1 was activated or ULK1 was inactivated by MBX-2982. However, downstream targets of mTORC1, phosphorylation of ribosomal protein $\mathrm{S} 6$ kinase $\beta-1$ (p70S6K) and eukaryotic translation initiation factor
4E-binding protein 1 (4EBP1), were inhibited by MBX-2982 (Fig. 5f). In addition, ULK1 phosphorylation increased at $24 \mathrm{~h}$ exposure of MCF-7 cells to MBX-2982 (Fig. 5f). Protein components that elongate autophagosomes, ATG5, ATG7 and ATG12 were also not significantly affected by MBX-2982 (Fig. 5g). The data suggest 


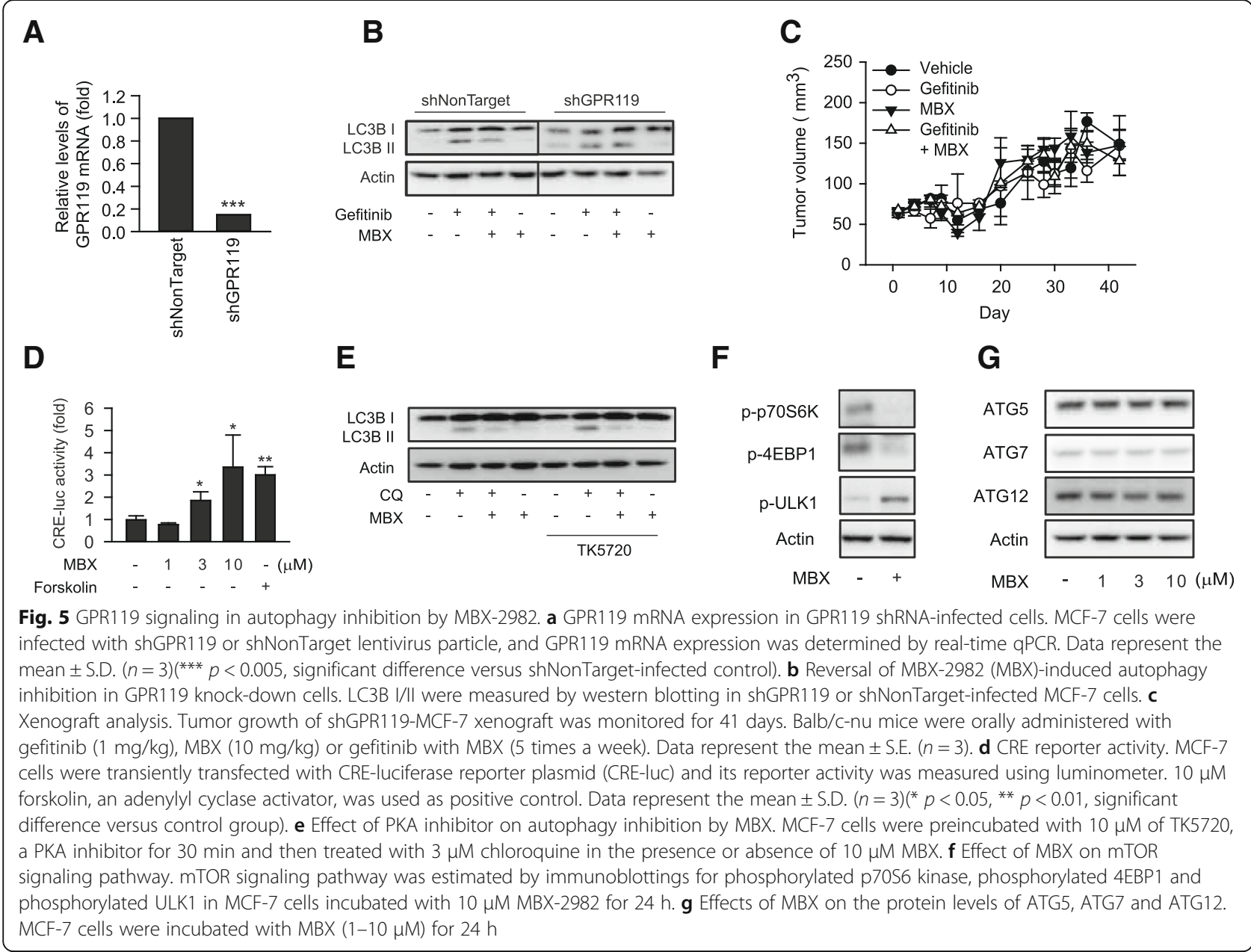

that autophagy inhibition by GPR119 agonist is not mediated through classical GPR119 signaling or the PI3K/ mTORC1/ULK1 pathway.

\section{Metabolic shift by MBX-2982 and inhibition of gefitinib-induced autophagy by lactate}

We previously reported that MBX-2982 activated AMP-activated protein kinase (AMPK), and pleiotrophic roles of AMPK have been investigated in many types of cancer [22, 29]. Hence, we further investigated a potential role of AMPK in autophagy inhibition by GPR119 agonist. We found that AMPK was activated in MCF-7 cells by MBX-2982, as evidenced by phosphorylation of AMPK or acetyl CoA carboxylase (ACC), a downstream target of AMPK (Fig. 6a), but the activation of upstream kinases such as liver kinase B1 (LKB1) and transforming growth factor- $\beta$-activating kinase 1 (TAK1), was not observed (data not shown). On the other hand, cellular ATP production was sustainedly dimished by MBX-2982 in MCF-7 cells (Fig. 6b). Because ATP production mainly relies on mitochondrial oxidative phosphorylation (OXPHOS) [29], we hypothesized that mitochondrial function might be defective in MBX-2982 treated cells. Mitostress assays revealed that exposure of MCF-7 cells to MBX-2982 or GSK1292263 for $30 \mathrm{~min}, 2$ or 6 h continuously suppressed oxygen consumption rate (OCR), which reflects ATP production capacity in mitochondria (Fig. 6c, left). Elevated extracellular acidification rate (ECAR) indicates that energy metabolism inclines toward glycolysis. Both the GPR119 agonists increased ECAR in MCF-7 cells (Fig. 6c, right). We then assessed the effects of 2-deoxlyglucose (2-DG), a competitive inhibitor of glycolysis. 2-DG restored the elevated ECAR without OCR change in MBX-2982-treated MCF-7 cells (Fig. 6d). Lactate is produced by lactate dehydrogenase A (LDHA) during the process of glycolysis. GSK2387808, a LDH inhibitor, also suppressed MBX-2982-mediated increases in ECAR without changing OCR (Fig. 6e). These results domonstrate that GPR119 agonsits cause a metabolic shift toward glycolysis in MCF-7 cells.

To further investigate the role of enhanced glycolysis by GPR119 agonists, we determined intracellular and extracellular levels of lactate, an end product of glycolysis. Extracellular and intracellular levels of lactate were 


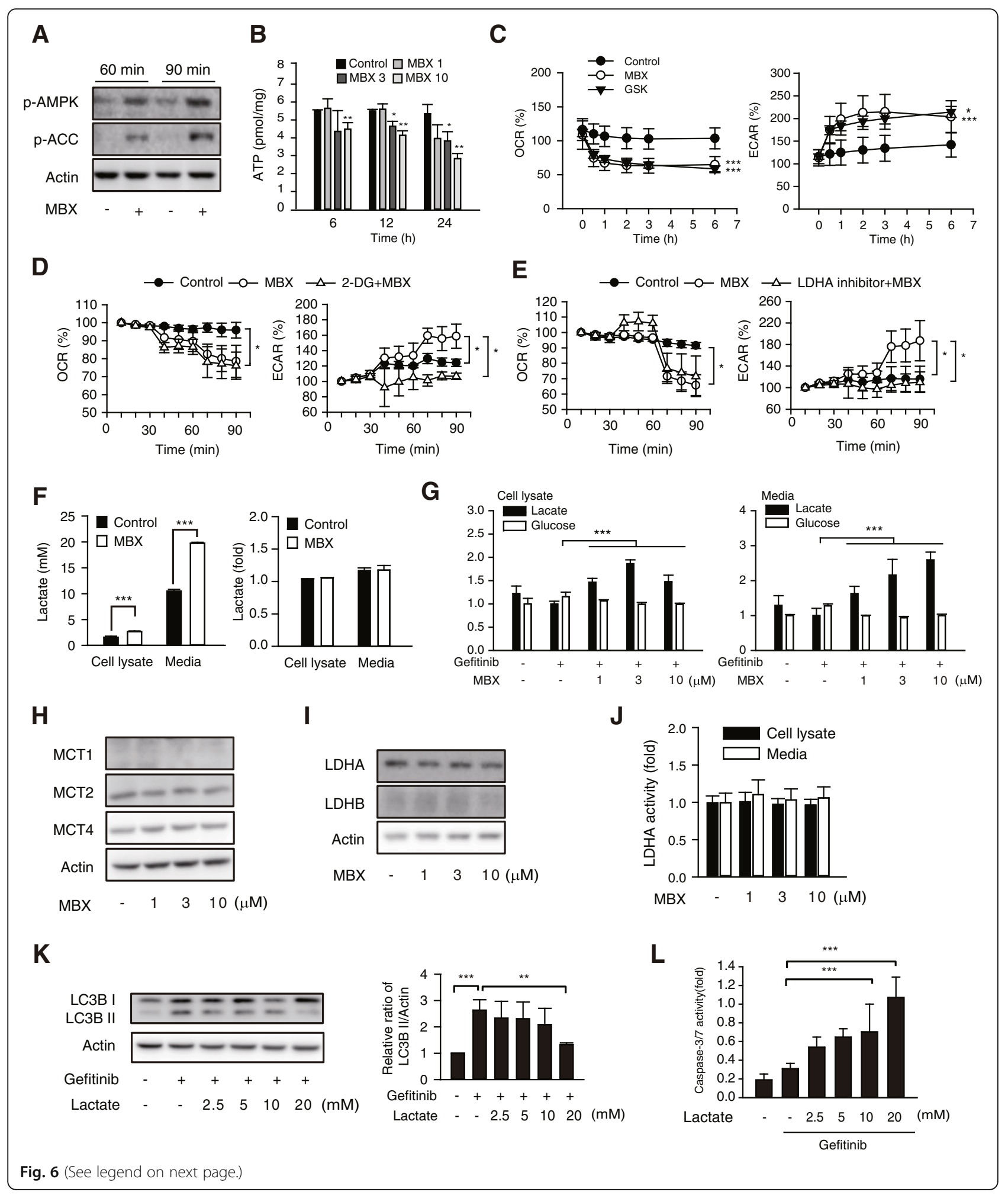


(See figure on previous page.)

Fig. 6 Metabolic shift by MBX-2982 and inhibition of gefitinib-induced autophagy by lactate. a AMPK activity was determined by immunoblottings for phosphorylated AMPK and phosphorylated ACC proteins in MCF-7 cells treated with $10 \mu \mathrm{M}$ MBX-2982. b ATP content was determined by ATP assay kit in MCF-7 cells. Cells were treated with MBX-2982 (1-10 $\mu$ M). c Effects of GPR119 agonists on mitochondrial OXPHOS and glycolysis in MCF-7 cells. d MCF-7 cells were pretreated with or without 2-deoxyglucose (2-DG, $50 \mathrm{mM}$ ) for $30 \mathrm{~min}$ and incubated with $10 \mu \mathrm{M} \mathrm{MBX}$. e MCF-7 cells were pretreated with or without GSK2837808 (LDH inhibitor, $10 \mu \mathrm{M}$ ) for $30 \mathrm{~min}$ and incubated with $10 \mu \mathrm{M} \mathrm{MBX}$. f MBX-induced lactate production in MCF-7 (left) and shGPR119-MCF-7 cells (right). Lactate concentration was assessed by 1H-NMR or lactate assay kit in total cell lysates and culture media. g MCF-7 cells were incubated with $10 \mu \mathrm{M}$ gefitinib in the presence or absence of MBX for $24 \mathrm{~h}$ and concentrations of glucose and lactate were determined by $1 \mathrm{H}-\mathrm{NMR}$ in total cell lysates (left) and culture media (right). $\mathbf{h}$ and $\mathbf{i}$ MCF-7 cells were treated with MBX for $24 \mathrm{~h}$ and protein expression of lactate transporters and lactate converting enzymes were measured by western blottings. $\mathbf{j}$ MCF-7 cells were treated with MBX-2982 for $24 \mathrm{~h}$ and LDHA activity was determined by LDH assay kit. k MCF-7 cells were incubated with $10 \mu \mathrm{M}$ gefitinib in the presence or absence of lactate (2.5-20 mM) for $24 \mathrm{~h}$, and LC3B I/II were measured by immunoblottings. I Caspase3/7 activation by gefitinib with lactate. MCF-7 cells were treated gefitinib (10 $\mu \mathrm{M})$ with or without lactate $(5-20 \mathrm{mM})$ for $72 \mathrm{~h}$. Data represent the mean \pm S.D. $(n=3) .{ }^{*} p<0.05,{ }^{* *} p<0.01,{ }^{* * *} p<0.005$ significanct difference between the two indicated groups

1.8-fold increased by MBX-2982, and lactate in media even reached $20 \mathrm{mM}$ (Fig. 6f, left). In shGPR119-MCF-7 cells, increased lactate by MBX-2982 was not detected (Fig. 6f, right). We also found that lactate levels in either cell lysates or culture media also increased by MBX-2982 in MCF-7 cells treated with gefitnib, while intracellular amd extracellular glucose contents were slightly decreased (Fig. 6g). To clarify the effects of MBX-2982 in cellular pathways of lactate production, protein levels for MCT1/2, influx transporters of lactate and MCT4, an efflux transporter of lactate, were quantified. Expression of the transporters did not change with MBX-2982 (Fig. 6h). LDHA protein and enzyme activity were not altered by MBX-2982 (Fig. 6i and j). LDHB, which catalyzes conversion of lactate to pyruvate, was not detected in MCF-7 cells (Fig. 6i).

We then tested whether lactate production is involved in autophagy inhibition by MBX-2982. Given the detected concentration of lactate in culture media (Fig. 6f), 2.5$20 \mathrm{mM}$ lactate was cotreated with gefitinib in MCF-7 cells. Interestingly, the LC3B II expression induced by geifinib was inhibited by $20 \mathrm{mM}$ lactate (Fig. 6k). We further ascertained that co-incubation of MCF-7 cells with 10-20 mM lactate and gefitinib synergistically increased caspase-3/7 activity (Fig 6l). Thus, GPR119 agonist-mediated lactate production may lead to autophagy inhibition and potentiated cancer cell apoptosis with EGFR-TKI.

\section{Discussion}

Chemotherapy resistance frequently occurs in cancer patients and thereby restricts the clinical benefit of the chemotherapeutic agents. The acquired resistance could be cured by the combination with other drugs that discard the resistance mechanism. For example, colorectal cancer harboring KRAS mutation shows the resistance to cetuximab, an EGFR monoclonal antibody. Mitogen-activated protein kinase kinase (MEK) inhibitor could increase the effect of cetuximab through blocking Ras-Raf pathway [30]. Because fulvestrant (pure estrogen receptor antagonist)-resistant breast cancer frequently shows the upregulation of mTOR pathway, the combination of fulvestrant and mTOR inhibitor is more efficious than fulvestrant alone [31]. Autophagy progression is known to be associated with cancer cell survival mechanism in the target therapies [32]. In fact, autophagy inhibitors such as chloroquine and bafilomycin A are cytotoxic to cancer cells [33], and several ongoing clinical trials are using chloroquine alone or the combination of chloroquine with taxane in breast cancer patients (ClinicalTrials.gov Identifier: NCT02333890 and NCT01446016).

GPR119 activation stimulates insulin and GLP-1 secretion in the pancreas and gastrointestinal tract and both the activities are related to Gos protein-dependent cAMP secretion [34]. In addition, GPR119 expression is upregulated by oxidized low-density lipoprotein in THP-1 human monocyte cell line, and GPR119 overexpression inhibits the development of atherosclerosis in apoE-null mice [35]. It has been shown that some GPCRs are involved in the regulation of autophagy, thus the ligand of these GPCRs are possible to use for autophagy-related diseases [36]. We observed that GPR119 expressed in human breast cancer cell lines and tumor tissues, and GPR119 agonists with gefitinib additively suppressed the growth of breast cancer cells and induced intrinsic apoptosis. Moreover, combination of GPR119 agonist with 4-hydroxytamoxifen in MCF-7 cells as well as with sorafenib in HepG2 cells enhanced the anti-cancer effect of each target therapy. Although GPR119 agonist did not affect cell cycle progression in MCF-7 cells, EGFR TKI-mediated autophagy stimulation was reversed by MBX-2982 treatment. Thus, the anti-autophagy effect of GPR119 ligand may not be specific for cancer cell types or TKI classification.

Here, we also found that mTORC1 signaling was suppressed by GPR119 agonist, which is evidenced by decreased phosphorylations of p70S6K and 4EBP1 by MBX-2982 in MCF-7 cells. Because the activation of p70S6K and 4EBP1 is important for mRNA translation [37], GPR119 agonsit-induced mTORC1 inhibition may lead to the depletion of protein synthesis in cancer cells. Moreover, autophagy supplies recycling nutrients such as amino acids, nucleotides and fatty acids through the 
degradation of intracellular substrates [38]. Metabolites analysis using LC/Ms./Ms. showed that many animo acids as well as nucleotides were dimished by MBX-2982 treatment in MCF-7 cells (Additional file 2: Figure S2). These results support a notion that GPR119 stimulation in cancer cells results in the deficiency of building blocks for proteins.

Apoptosis induction and autophagy inhibition by a GPR119 agonist might be related to changes in cancer cell metabolism instead of canonical signaling pathway(s) of GRP119. Inhibition of autophagy by MBX-2982 was not restored by cAMP/PKA inhibitor. Instead, our data demonstrated that MBX-2982 suppressed mitochondrial OXPHOS with increased lactate production by glycolysis stimulation. Although future study is needed on why reduced OXPHOS and enhanced glycolysis occur at the same time, intracellular ATP production was eventually decreased by MBX-2982. We suggest that increased lactate production is the cause of autophagy inhibition by MBX-2982. The molecular mechanism for the suppression of autophagosome formation by lactate remains unclear, but may be associated with intracellular $\mathrm{pH}$ changes. Although autophagolysosome activity is likely to be amplified by physiologically acidic pH (<6.4) [39], GPR119 agonist-induced supraphysiological lactate production could suppress autophagosome formation and eventually induce cancer cell death. Intracellular $\mathrm{pH}$ regulation via MCTs or LDHs could be important for cancer cell survival. Indeed, inhibitors of MCTs or LDHs are a potential therapeutic target in cancer [40]. Another possibility is that specific lactate receptor(s) may be involved in autophagosome suppression by lactic acid.

GPR81 is activated by extracellular lactate [41-44]. GPR81 is involved in the lipolysis inhibition in adipocytes and in the anti-inflammation in macrophages [41, 42]. Moreover, GPR81 is upregulated in malignant cancers and involved in cell migration and metastasis [44]. Shen et al. have shown that extracellular lactate induces caspase-3-dependent apoptosis through Bax upregulation in GPR81-transfected N2A (mouse neuroblastoma) cells [43]. However, when GPR81 was depleted in MCF-7 cells (Additional file 3: Figure S3A), MBX-2982-mediated autophagy inhibition was not altered (Additional file 3: Figure S3B), indicating that GPR81 may not be associated with lactate-induced autophagy inhibition. From the view of tumor microenvironment, infiltrated macrophages and associated stromal cells promote tumor progression [45]. Tumor-associated macrophages exacerbate tumor progression via the secretion of several cytokines such as interleukin-1 $\beta$ and interleukin-6 [45, 46]. GPR119 agonist-mediated lactate production could suppress the inflammatory immune cells producing tumor-promoting cytokines via GPR81 activation. In support of this notion, robust interleukin- $1 \beta$ and interleukin- 6 production were observed in macrophage from GPR81-null mice [41].
The Yeom research group first identified N-myc downstream-regulated gene 3 protein (NDRG3) as a novel binding partner of intracellular lactate [47]. NDRG3 protein bound to lactate is upregulated by enhanced protein stability and accelerates cell growth and angiogenesis of cancer cells by activating the Raf-extracellular signal-regulated kinase pathway [47]. However, NDRG3 protein expression was not detected in MCF-7 cells exposed to MBX-2982 (Additional file 3: Figure S3C). Hence, autophagy inhibition by GPR119 agonist may not be associated with GPR81-dependent signaling by extracellular lactate or NDRG3-dependent signaling by intracellular lactate.

Because a previous study has reported that increased glycolysis and lactate production triggers breast cancer cell stemness and tumor growth in MCF-7 cells [48], GPR119 activation could be related with cancer cell stemness. To assess whether GPR119 agonist induces cancer cell stemness in MCF-7 cells, we performed spheroid formation assay in ultra-low attachment (ULA) plate condition. $10^{3}$ MCF-7 cells cultured on ULA plate were incubated with vehicle or GPR119 agonist for $96 \mathrm{~h}$. Interestingly, the spheroid volume was significantly diminished by MBX-2982 (Additional file 3: Figure S3D), which suggest that GPR119 agonist does not induce cancer cell stemness, rather inhibits spheroid formation. Martinez-Outschoorn et al. also described that metformin exerts its anti-cancer effects via inducing aerobic glycolysis that has been proposed as a cause of cancer [48]. Hence, the revaluation of glycolysis and lactate production on the cancer cell stemness would be required.

The inhibition of mitochondrial OXPHOS by MBX-2982 appeared to be partially related to a direct action of GPR119 agonist on mitochondria. When we examined mitochondrial stress in GPR119-knockdown MCF-7 cells, GRP119 receptor depletion significantly restored mitochondrial stress (OCR decrease) induced by $3 \mu \mathrm{M}$ MBX-2982. However, OCR decrease was not restored in GPR119 knockdown cells incubated with $10 \mu \mathrm{M}$ MBX-2982 (Additional file 4: Fig. S4A). Considering our finding that high concentration of MBX-2982 inhibited OCR in receptor-independent manner, we tested the direct effect of MBX-2982 on mitochondrial complex activity. We found that $10^{-10}-10^{-6} \mathrm{M}$ MBX-2982 marginally inhibited the enzyme activity of complex I in isolated mitochondria (Additional file 4: Figure S4B). After $3 \mathrm{~h}$ incubation of MCF-7 cells with $10 \mu \mathrm{M}$ MBX-2982, approximately $10 \%$ of MBX-2982 was detected in a mitochondrial fraction compared to the amount in whole cell lysates, using LC/Ms./Ms. analysis (Additional file 4: Figure S4C). Hence, a MBX-2982-induced metabolic shift in cancer cells may result from a direct action on mitochondria as well as GPR119 receptor-dependent activity. It has been suggested that several mitochondrial targeting agents could be adopted for cancer chemotherapies. CPI-613, an $\alpha$-linolic acid derivative, selectively targets altered mitochondrial function and induces cell death in H460 lung cancer cells [49]. Metformin, an 
AMPK activator, inhibits complex I and is used to treat diverse types of cancer in clinical trials [50].

\section{Conclusion}

GPR119 agonists reduced mitochondrial OXPHOS and stimulated glycolysis in breast cancer cells, with consequent overproduction of lactate that inhibited autophagosome formation. Because autophagy is crucial for the survival of cancer cells exposed to TKIs, GPR119 agonists potentiated the anticancer effects of TKIs. Our findings indicate that the combination of GPR119 agonist with TKI would be a possible therapeutic approach for cancer chemotherapy.

\section{Additional files}

Additional file 1: Figure S1. Additive effects of GPR119 agonists on cell proliferation inhibition by gefitinib in breast cancer cell lines. (A, B) Additive effect of GSK1292263 (GSK) on cell proliferation inhibition by gefitinib in MCF-7 (A) and MDA-MB-231 cells. MCF-7 and MDA-MB-231 cells were treated with $10 \mu \mathrm{M}$ gefitinib and 1-10 $\mu \mathrm{M}$ GSK (left), or GSK alone (right). (C) Additive effects of MBX-2982 (MBX) on cell proliferation inhibition by gefitinib in SK-BR-3 and MDA-MB-468 cells. (D) Combined effect of gefitinib with oleoylethanolamine (OEA) on cell proliferation of MCF-7 cells. The cells were incubated with $10 \mu \mathrm{M}$ gefitinib in the presence or absence of $10 \mathrm{mM}$ OEA. Relative proliferation rate was calculated by Incucyte ${ }^{\oplus}$ ZOOM basic analyzer. Data represent the mean \pm S.D. $(n=6)\left({ }^{* *} p<0.005\right.$, significant difference between the indicated two groups). (PDF $119 \mathrm{~kb}$ )

Additional file 2: Figure S2. Identification of cellular metabolites with significant differences $(p<0.05)$ in MBX-2982-treated MCF-7 cells. MCF-7 cells were treated with $10 \mu \mathrm{M}$ MBX-2982 for $24 \mathrm{~h}$, and the relative cellular contents of metabolites were determined by LC/Ms./Ms. Data represent the mean \pm S.D. $(n=3)$. (PDF $118 \mathrm{~kb})$

Additional file 3: Figure S3. Roles of GPR81 and NDRG3 in autophagy inhibition by MBX-2982. (A) GPR81 mRNA expression in GPR81 shRNA-infected cells. MCF-7 cells were infected with shGPR81 or shNonTarget lentivirus particle, and GPR81 mRNA expression was determined by real-time qPCR. Data represent the mean \pm S.D. $(n=3)\left({ }^{* *} p<0.005\right.$, significant difference versus shNonTarget infected control). (B) Effect of GPR81 shRNA on autophagy inhibition by MBX-2982. LC3B I/II were determined by immunoblotting in shRNA control or shGPR81-infected MCF-7 cells. Both the cells were treated with $10 \mu \mathrm{M}$ gefitinib in the presence or absence of $10 \mu \mathrm{M}$ MBX-2982 for 24 h. Data represent the mean \pm S.D. $(n=3){ }^{*} p<0.05$, significant difference between the indicated two groups). (C) Protein expression of NDRG3 (intracellular lactate receptor). MCF-7 cells were treated with $10 \mu \mathrm{M}$ gefitinib in the presence or absence of $10 \mu \mathrm{M}$ MBX-2982 for $24 \mathrm{~h}$, and proten level of NDRG3 was monitored by immunoblotting. (D) Spheroid formation assay. $10^{3} \mathrm{MCF}-7$ cells were incubated with $10 \mu \mathrm{M}$ gefitinib and/or $10 \mu \mathrm{M}$ MBX-2982 for $96 \mathrm{~h}$ on ULA plate. Left, Representative spheroid images. Right, Spheroid volume. Data represent the mean \pm S.D. $(n=3)\left({ }^{* *} p<0.01\right.$, significant difference between the indicated two groups). (PDF $119 \mathrm{~kb}$ )

Additional file 4: Figure S4. Mitochondrial distribution of MBX-2982 and complex I inhibition. (A) GPR119-independent inhibition of OCR by $10 \mu \mathrm{M}$ MBX-2982. OCR and ECAR were measured by XFp analyzer in both non-target shRNA- or GPR119 shRNA-infected MCF-7 cells. Both the cell types were treated with MBX-2982 (1-10 $\mu \mathrm{M})$. (B) Mitochondrial complex I inhibition by MBX-2982. Complex I inhibition by MBX-2982 $\left(10^{-10}, 10^{-8}\right.$ and $\left.10^{-6} \mathrm{M}\right)$ was tested by mitostress test kit. Rotenone (100 nM) was used as a positive control of complex I inhibition. (C) Relative amounts of MBX-2982 were determined by LC/Ms./Ms. MCF-7 cells were incubated with MBX-2982 $(10 \mu \mathrm{M})$ for $6 \mathrm{~h}$ and then homogenized. Cellular component fraction was isolated by sucrose gradient method. (PDF $107 \mathrm{~kb}$ )

\section{Abbreviations}

3-MA: 3-methyladenine; 4EBP1: Eukaryotic translation initiation factor 4Ebinding protein 1; ACC: Acetyl-CoA carboxylase; AMPK: AMP-activated protein kinase; ATG3: Autophagy related 3; ATG5: Autophagy related 5; ATG7: Autophagy related 7; CRE: CAMP responsive element;

ECAR: Extracellular acidification rate; EGFR: Epidermal growth factor receptor; GPCRs: G-protein coupled receptors; LC3B: Microtubule associated protein 1 light chain 3 beta; LDH: Lactate dehydrogenase; MCT1: Monocarboxylate transporter 1; MCT2: Monocarboxylate transporter 2; MCT4: Monocarboxylate transporter 4; mTOR: mechanistic target of rapamycin kinase; NDRG3: N-myc downstream regulated gene member 3; NMR: Nuclear magenetic resonance; NSCLC: Non-small cell lung cancer; OCR: Oxygen consumption rate;

OXPHOS: Oxidative phosphorylation; p70S6K: Ribosomal protein S6 kinase B1 PARP: Poly(ADP-ribose) polymerases; PBS: Phosphate-buffered saline; PI: Propidium iodide; PI3K: Phosphatidylinositol-4,5-bisphosphate 3-kinase; PKA: Protein kinase A; TEM: Transmission electron microscopy; TKIs: Tyrosine kinase inhibitors; TNBC: Triple negative breast cancer; ULA: Ultra-low attachment; ULK1: Unc-51 like autophagy activating kinase 1

\section{Acknowledgements}

We thank Dr. Kim J (University of Florida, Gainesville, FL, USA) for donating of GFP-LC3B plasmid.

\section{Funding}

This work was supported by the National Research Foundation of Korea (NRF) grants [NRF-2018R1A2B2003590 (Data collection, analysis, interpretation and writing the manuscript) and 2017R1A4A1015860 (Design of study and data collection)]

\section{Availability of data and materials}

The datasets used and/or analysed during the current study are available from the corresponding author on reasonable request.

\section{Authors' contributions}

Im JH and Kang KW designed and supervised of the the study. Kim SY and other authors performed experiments. Chio SY and Lee JS helped to analyze human tissues. All authors read and approved the final manuscript.

\section{Ethics approval and consent to participate}

All human tissues were obtained with patients' written informed consent and approved by the ethics committee of Chungnam National University. Animal studies were approved by Laboratory Animal Ethics Committee of Seoul National University.

\section{Consent for publication}

Not applicable.

\section{Competing interests}

The authors declare that they have no competing interests.

\section{Publisher's Note}

Springer Nature remains neutral with regard to jurisdictional claims in published maps and institutional affiliations.

\section{Author details}

${ }^{1}$ College of Pharmacy and Research Institute of Pharmaceutical Sciences, Seoul National University, Seoul, Republic of Korea. ${ }^{2}$ Department of Nuclear Medicine, College of Medicine, Seoul National University, Seoul, Republic of Korea. ${ }^{3}$ College of Pharmacy, Dankook University, Cheonan-si, Republic of Korea. ${ }^{4}$ Natural Product Research Institute, College of Pharmacy, Seoul National University, Seoul, Republic of Korea. ${ }^{5}$ Molecular Recognition Research Center, Korea Institute of Science and Technology, Seoul, Republic of Korea. ${ }^{6}$ College of Medicine, Chungnam National University, Daejeon, Republic of Korea.

Received: 15 July 2018 Accepted: 31 October 2018

Published online: 29 November 2018

\section{References}

1. Liu TC, et al. Role of epidermal growth factor receptor in lung cancer and targeted therapies. Am J Cancer Res. 2017;7(2):187-202.

2. Matsuda N, et al. Early clinical development of epidermal growth factor receptor targeted therapy in breast cancer. Expert Opin Investig Drugs. 2017;26(4):463-79. 
3. Boya P, Reggiori F, Codogno P. Emerging regulation and functions of autophagy. Nat Cell Biol. 2013;15(7):713-20.

4. Kaur J, Debnath J. Autophagy at the crossroads of catabolism and anabolism. Nat Rev Mol Cell Biol. 2015;16(8):461-72.

5. Wang WJ, et al. Induction of Autophagic death in Cancer cells by agonizing TR3 and attenuating Akt2 activity. Chem Biol. 2015;22(8):1040-51.

6. Xie ZG, Xie Y, Dong QR. Inhibition of the mammalian target of rapamycin leads to autophagy activation and cell death of MG63 osteosarcoma cells. Oncol Lett. 2013;6(5):1465-9.

7. Cook KL, et al. Hydroxychloroquine inhibits autophagy to potentiate antiestrogen responsiveness in ER+ breast cancer. Clin Cancer Res. 2014;20(12):3222-32.

8. Golden EB, et al. Chloroquine enhances temozolomide cytotoxicity in malignant gliomas by blocking autophagy. Neurosurg Focus. 2014;37(6):E12.

9. Kebede MA, et al. Lipid receptors and islet function: therapeutic implications? Diabetes Obes Metab. 2009;11(Suppl 4):10-20.

10. Wu Q, et al. Identification of G-protein-coupled receptor 120 as a tumorpromoting receptor that induces angiogenesis and migration in human colorectal carcinoma. Oncogene. 2013;32(49):5541-50.

11. Fukushima K, et al. Different roles of GPR120 and GPR40 in the acquisition of malignant properties in pancreatic cancer cells. Biochem Biophys Res Commun. 2015;465(3):512-5.

12. Tang Y, et al. G-protein-coupled receptor for short-chain fatty acids suppresses colon cancer. Int J Cancer. 2011;128(4):847-56.

13. Sivaprakasam S, Prasad PD, Singh N. Benefits of short-chain fatty acids and their receptors in inflammation and carcinogenesis. Pharmacol Ther. 2016;164:144-51.

14. Hardy $\mathrm{S}$, et al. Oleate promotes the proliferation of breast cancer cells via the G protein-coupled receptor GPR40. J Biol Chem. 2005;280(14):13285-91.

15. Nehra D, et al. Docosahexaenoic acid, G protein-coupled receptors, and melanoma: is $\mathrm{G}$ protein-coupled receptor 40 a potential therapeutic target? J Surg Res. 2014;188(2):451-8.

16. Yang JW, et al. GPR119: a promising target for nonalcoholic fatty liver disease. FASEB J. 2016;30(1):324-35.

17. Debnath J, Muthuswamy SK, Brugge JS. Morphogenesis and oncogenesis of MCF-10A mammary epithelial acini grown in three-dimensional basement membrane cultures. Methods. 2003;30(3):256-68.

18. Jeong $\mathrm{HG}$, et al. Novel role of Pin 1 induction in type II collagen-mediated rheumatoid arthritis. J Immunol. 2009;183(10):6689-97.

19. Masuda $\mathrm{H}$, et al. Role of epidermal growth factor receptor in breast cancer Breast Cancer Res Treat. 2012;136(2):331-45.

20. Ali R, Wendt MK. The paradoxical functions of EGFR during breast cance progression. Signal Transduct Target Ther. 2017;2:16042.

21. Tallarida RJ. Quantitative methods for assessing drug synergism. Genes Cancer. 2011;2(11):1003-8.

22. Yang JW, et al. Therapeutic application of GPR119 ligands in metabolic disorders. Diabetes Obes Metab. 2018;20(2):257-69.

23. Childs $A C$, et al. Doxorubicin treatment in vivo causes cytochrome $C$ release and cardiomyocyte apoptosis, as well as increased mitochondrial efficiency, superoxide dismutase activity, and Bcl-2:Bax ratio. Cancer Res. 2002;62(16):4592-8.

24. Suh $\mathrm{DH}$, et al. Unfolded protein response to autophagy as a promising druggable target for anticancer therapy. Nutr Phys Act Aging Obes Cancer. 2012:1271:20-32.

25. Mizushima N, Yoshimori T, Levine B. Methods in mammalian autophagy research. Cell. 2010;140(3):313-26.

26. Lazzeroni M, et al. Oral low dose and topical tamoxifen for breast cancer prevention: modern approaches for an old drug. Breast Cancer Res. 2012; 14(5):214.

27. Abdel-Rahman O, Fouad M. Sorafenib-based combination as a first line treatment for advanced hepatocellular carcinoma: a systematic review of the literature. Crit Rev Oncol Hematol. 2014;91(1):1-8.

28. Hansen HS, et al. GPR119 as a fat sensor. Trends Pharmacol Sci. 2012;33(7): 374-81.

29. Zadra G, Batista JL, Loda M. Dissecting the dual role of AMPK in Cancer: from experimental to human studies. Mol Cancer Res. 2015;13(7):1059-72.

30. Nurwidya F, et al. Molecular mechanisms contributing to resistance to tyrosine kinase-targeted therapy for non-small cell lung cancer. Cancer Biol Med. 2012;9(1):18-22.

31. Kornblum N, et al. Randomized Phase II Trial of Fulvestrant Plus Everolimus or Placebo in Postmenopausal Women With Hormone Receptor-Positive, Human Epidermal Growth Factor Receptor 2-Negative Metastatic Breast Cancer Resistant to Aromatase Inhibitor Therapy: Results of PrE0102. J Clin Oncol. 2018;36(16):1556-63.
32. White E. Deconvoluting the context-dependent role for autophagy in cancer. Nat Rev Cancer. 2012;12(6):401-10.

33. Amaravadi RK, et al. Autophagy inhibition enhances therapy-induced apoptosis in a Myc-induced model of lymphoma. J Clin Invest. 2007;117(2): 326-36.

34. Ritter K, et al. G protein-coupled receptor 119 (GPR119) agonists for the treatment of diabetes: recent Progress and prevailing challenges. J Med Chem. 2016;59(8):3579-92.

35. Hu YW, et al. A lincRNA-DYNLRB2-2/GPR119/GLP-1R/ABCA1-dependent signal transduction pathway is essential for the regulation of cholesterol homeostasis. J Lipid Res. 2014;55(4):681-97.

36. Wauson EM, et al. G protein-coupled receptors and the regulation of autophagy. Trends Endocrinol Metab. 2014;25(5):274-82.

37. Kim J, et al. AMPK and mTOR regulate autophagy through direct phosphorylation of Ulk1. Nat Cell Biol. 2011;13(2):132-41.

38. White E, Mehnert JM, Chan CS. Autophagy, metabolism, and Cancer. Clin Cancer Res. 2015;21(22):5037-46.

39. Berezhnov AV, et al. Intracellular pH modulates autophagy and Mitophagy. J Biol Chem. 2016;291(16):8701-8.

40. Pouyssegur J, Dayan F, Mazure NM. Hypoxia signalling in cancer and approaches to enforce tumour regression. Nature. 2006;441(7092):437-43.

41. Ranganathan P, et al. GPR81, a cell-surface receptor for lactate, regulates intestinal homeostasis and protects mice from experimental colitis. J Immunol. 2018;200(5):1781-9.

42. Ahmed $\mathrm{K}$, et al. An autocrine lactate loop mediates insulin-dependent inhibition of lipolysis through GPR81. Cell Metab. 2010;11(4):311-9.

43. Shen $Z$, et al. Inhibition of $G$ protein-coupled receptor 81 (GPR81) protects against ischemic brain injury. CNS Neurosci Ther. 2015;21(3):271-9.

44. Roland CL, et al. Cell surface lactate receptor GPR81 is crucial for cancer cell survival. Cancer Res. 2014;74(18):5301-10.

45. Wan S, et al. Tumor-associated macrophages produce interleukin 6 and signal via STAT3 to promote expansion of human hepatocellular carcinoma stem cells. Gastroenterology. 2014;147(6):1393-404.

46. Terlizzi M, et al. IL-1alpha and IL-1 beta-producing macrophages populate lung tumor lesions in mice. Oncotarget. 2016;7(36):58181-92.

47. Lee DC, et al. A lactate-induced response to hypoxia. Cell. 2015;161(3):595609.

48. Martinez-Outschoorn UE, et al. Ketones and lactate increase cancer cell "stemness", driving recurrence, metastasis and poor clinical outcome in breast cancer: achieving personalized medicine via Metabolo-genomics. Cell Cycle. 2011;10(8):1271-86.

49. Lycan TW, et al. A phase II clinical trial of CPI-613 in patients with relapsed or refractory small cell lung carcinoma. PLoS One. 2016;11(10):e0164244.

50. Pernicova I, Korbonits M. Metformin--mode of action and clinical implications for diabetes and cancer. Nat Rev Endocrinol. 2014;10(3):143-56.

Ready to submit your research? Choose BMC and benefit from:

- fast, convenient online submission

- thorough peer review by experienced researchers in your field

- rapid publication on acceptance

- support for research data, including large and complex data types

- gold Open Access which fosters wider collaboration and increased citations

- maximum visibility for your research: over $100 \mathrm{M}$ website views per year

At $\mathrm{BMC}$, research is always in progress.

Learn more biomedcentral.com/submissions 